\title{
Erratum to: Evaluation of Urban Local-Scale Aerodynamic Parameters: Implications for the Vertical Profile of Wind Speed and for Source Areas
}

\author{
Christoph W. Kent ${ }^{1}$ (D) - Sue Grimmond ${ }^{1}$ (D) - Janet Barlow ${ }^{1} \cdot$ David Gatey $^{2}$ • \\ Simone Kotthaus $^{1}$ (D) Fredrik Lindberg ${ }^{3}$. Christos H. Halios $^{1}$
}

Published online: 3 June 2017

(C) Springer Science+Business Media Dordrecht 2017

\section{Erratum to: Boundary-Layer Meteorol DOI 10.1007/s10546-017-0248-z}

In the original publication of the article, there are typographical errors. Equation 4 should be written as:

$$
\operatorname{Rau}_{z_{d}}=\left(1+\left\{\frac{\exp \left[-\left(C_{d l} 2 \lambda_{f}\right)^{0.5}\right]-1}{\left(C_{d l} 2 \lambda_{f}\right)^{0.5}}\right\}\right) H_{a v} .
$$

And Eq. 8 should be written as:

$$
\operatorname{Bot}_{z_{0}}=\left(z-z_{d}\right) \exp \left(-\frac{\kappa}{\sqrt{0.5 \lambda_{f} C_{D b}}}\right),
$$

with the in-text formula before Eq. 7 reading $\tau=0.5 C_{D b} \rho u_{\mathrm{z}}^{2} \lambda_{\mathrm{f}}$, where $\tau$ is the drag force per unit ground area. All other notation is defined within the original article. The errors are only typographical and therefore do not affect results. We apologise for any inconvenience caused.

The online version of the original article can be found under doi:10.1007/s10546-017-0248-z.

Christoph W. Kent

C.W.Kent@pgr.reading.ac.uk

$凶 \quad$ Sue Grimmond

c.s.grimmond@reading.ac.uk

1 Department of Meteorology, Reading University, RG6 6UR Reading, UK

2 Risk Management Solutions, EC3R 8NB London, UK

3 Department of Earth Sciences, University of Gothenburg, 40530 Gothenburg, Sweden 